\title{
Engineering E. coli strain for conversion of short chain fatty acids to bioalcohols
}

\author{
Anu Jose Mattam and Syed Shams Yazdani*
}

\begin{abstract}
Background: Recent progress in production of various biofuel precursors and molecules, such as fatty acids, alcohols and alka(e)nes, is a significant step forward for replacing the fossil fuels with renewable fuels. A two-step process, where fatty acids from sugars are produced in the first step and then converted to corresponding biofuel molecules in the second step, seems more viable and attractive at this stage. We have engineered an Escherichia coli strain to take care of the second step for converting short chain fatty acids into corresponding alcohols by using butyrate kinase (Buk), phosphotransbutyrylase (Ptb) and aldehyde/alcohol dehydrogenase (AdhE2) from Clostridium acetobutylicum.

Results: The engineered E. coli was able to convert butyric acid and other short chain fatty acids of chain length C3 to C7 into corresponding alcohols and the efficiency of conversion varied with different E. coli strain type. Glycerol proved to be a better donor of ATP and electron as compared to glucose for converting butyric acid to butanol. The engineered E. coli was able to tolerate up to $100 \mathrm{mM}$ butyric acid and produced butanol with the conversion rate close to $100 \%$ under anaerobic condition. Deletion of native genes, such as fumarate reductase ( frdA) and alcohol dehydrogenase (adhE), responsible for side products succinate and ethanol, which act as electron sink and could compete with butyric acid uptake, did not improve the butanol production efficiency. Indigenous acyl-CoA synthetase (fadD) was found to play no role in the conversion of butyric acid to butanol. Engineered $E$. coli was cultivated in a bioreactor under controlled condition where $60 \mathrm{mM}$ butanol was produced within $24 \mathrm{~h}$ of cultivation. A continuous bioreactor with the provision of cell recycling allowed the continuous production of butanol at the average productivity of $7.6 \mathrm{mmol} / \mathrm{l} / \mathrm{h}$ until $240 \mathrm{~h}$.

Conclusions: E. coli engineered with the pathway from C. acetobutylicum could efficiently convert butyric acid to butanol. Other short chain fatty acids with the chain length of C3 to C7 were also converted to the corresponding alcohols. The ability of engineered strain to convert butyric acid to butanol continuously demonstrates commercial significance of the system.
\end{abstract}

Keywords: Engineered E. coli, Clostridium acetobutylicum, Butyric acid, Butanol, Fermentation

\section{Background}

Finding different means for production of biofuel molecules will help in gradual shift from usage of fossil fuels [1]. Ethanol so far has served the purpose of alternative fuel due to its easy and cost effective manufacturing process [2]. Butanol, however, is considered to be closer to the fossil fuel in terms of its energy density and hygroscopicity [3-5].

\footnotetext{
* Correspondence: shams@icgeb.res.in

Synthetic Biology and Biofuels Group, International Centre for Genetic Engineering and Biotechnology (ICGEB), Aruna Asaf Ali Marg, 110067 New Delhi, India
}

n-Butanol had traditionally been produced by Clostridium acetobutylicum through ABE fermentation [4]. C. acetobutylicum undergoes acidogenic phase, when it produces majorly acetic acid and butyric acid, followed by solventogenic phase, when it produces acetone, butanol and ethanol (ABE) mix [6]. There are several challenges to the $\mathrm{ABE}$ fermentation that prevented this technology from being commercially viable. Some of these challenges include high feedstock cost, low butanol titer, low butanol productivity and strain instability [4,7]. Therefore, engineering efforts have been made to construct non-native industry-friendly host to produce n-butanol. Here, butanol producing pathway from Clostridium sp. has been 
engineered in laboratory host for heterologous butanol production [8-11]. Further enhancement in butanol yield was made by replacing the pathway intermediate enzyme from the non-Clostridium host [12].

Research recently has been focused on separating alcohol or hydrocarbon production into two distinct biological events - fatty acids production in the first biological event and conversion of the fatty acids into various biofuel molecules in the second biological event. E. coli and Clostridium species have been used as the common host to fulfill these two functions. Free fatty acid production in engineered $E$. coli has been reported up to $0.3-0.4 \mathrm{~g} / \mathrm{g}$ glucose [13-15], while native Clostridium was shown to produce $0.45-0.54 \mathrm{~g}$ short chain fatty acid per gram of sugar $[16,17]$. Further, the long chain fatty acids were converted into alcohols and alka(e)nes by the engineered E. coli $[18,19]$ and short chain fatty acids were converted into alcohols using Clostridium sp. [20-22]. While pathway for independent biological conversion of long chain fatty acids to alcohol or alkane is well characterized and has been successfully used in the heterologous system, the pathway responsible for conversion of short chain fatty acids of C3-C7 length into either alcohol or alkane has been poorly characterized and has not been used in the heterologous system for such purpose. Moreover, native Clostridium host used for converting butyric acid to butanol needs to be constantly activated and regenerated through heat-shock and re-inoculation [20], thereby demanding development of more robust, industry friendly platform for this purpose.

Here, we report characterization of $C$. acetobutylicum pathway for conversion of short chain fatty acids into corresponding alcohols and successful engineering of the E. coli strain for performing this function. We further show that the yield of conversion is strain specific and internal E. coli enzymes do not play a significant role in this process. Most importantly, the process has been validated at the bioreactor level under controlled environment and the engineered $E$. coli cells have been used for continuous production of butanol.

\section{Results and discussion}

\section{Construction of $E$. coli strain for conversion of butyric} acid to butanol

Clostridium acetobutylicum is known to have an efficient pathway for production of butyric acid in the acidogenic phase as well as conversion of butyric acid to butanol in the solventogenic phase [23]. The production of butyric acid from butyryl-CoA during acidogenic phase happens through a reversible pathway consisting of two enzymes, i.e., butyrate kinase (Buk) and phosphotransbutyrylase (Ptb) [24], while conversion of butyric acid to butyryl-CoA during solventogenic phase occurs through CoA transferase (CoAT) enzyme with concurrent conversion of acetoacetyl-
CoA to acetoacetate [25]. Reversal of Buk-Ptb pathway for conversion of butyric acid to the intermediate butyryl-CoA is a more energy efficient process as compared to the equivalent $\beta$-oxidation pathway in $E$. coli for exogenous fatty acid activation and their subsequent degradation because clostridial pathway needs one ATP as against requirement of two ATP equivalence for E. coli acyl-CoA synthetase (FadD) based pathway [26]. Further, conversion of butyryl-CoA to butanol is more efficiently done by alcohol dehydrogenase from $C$. acetobutylicum as compared to the corresponding native enzyme of host $E$. coli due to its higher affinity towards the butyryl-CoA than the acetyl-CoA $[9,27]$. Therefore, three genes from Clostridium acetobutylicum, i.e., an operon containing phosphotransbutyrylase $(p t b)$ and butyrate kinase $(b u k)$ genes and aldehyde-alcohol dehydrogenase (adhE2) gene (Figure 1), which could be used for butyric acid to butanol conversion, were cloned in $\mathrm{PQE} 30$ vector and expressed in E. coli.

The heterologous expression of clostridial genes was tested in the engineered E. coli by Western blotting and enzyme assay. Western blotting was performed to assess the expression of two enzymes, Buk (whose gene was placed at the 3'end of ptb-buk operon) and AdhE2, where 6-histidine tag was incorporated during cloning as mentioned in the Methods section. Clear bands corresponding to the molecular weight of Buk $(\sim 39 \mathrm{kDa})$ and AdhE2 $(\sim 96 \mathrm{kDa})$ were observed on Western blot using antibody against 6-histidine tag (Figure 2A), indicating their efficient expression in $E$. coli $[27,28]$. The assay performed to assess enzyme activities of Ptb, Buk and AdhE2 showed $80 \mathrm{nmol} / \mathrm{min} / \mathrm{mg}, 8 \mathrm{nmol} / \mathrm{min} / \mathrm{mg}$ and $23 \mathrm{nmol} / \mathrm{min} / \mathrm{mg}$ of activities, respectively (Figure 2B). These values were largely close to the earlier reported enzyme activities for Ptb, Buk and AdhE2 in E. coli though we did observe variation in activities perhaps due to different cultivation condition, vector copy number and design of synthetic operon $[24,29]$. Significant enzyme expression and their activities were also observed in the uninduced cells, suggesting the leaking expression of these enzymes.

Conversion of butyric acid to butanol by the engineered E. coli (pQE-adhE2/ptb/buk) strain was tested with relevant controls. Neither pQE30 nor pQE-ptb/buk bearing cells could utilize butyric acid to produce butanol, suggesting all the three clostridial enzymes were needed to convert butyric acid to butanol (Figure 2C). The E. coli (pQE-adhE2/ $\mathrm{ptb} / \mathrm{buk}$ ) strain produced $1.7 \mathrm{mM}$ butanol from $2.3 \mathrm{mM}$ butyric acid after $120 \mathrm{~h}$ of incubation under anaerobic condition. Interestingly, we observed that butyrate concentration in the E. coli ( $\mathrm{pQE}$ - ptb/buk) strain increased when grown for 48 and 120 hours, leading to negative values for butyric acid consumption in Figure $2 \mathrm{C}$. This could be because both Ptb and Buk enzymes were reversible in nature and might be diverting some of the internal butyryl CoA pool of $E$. coli into butyrate. 


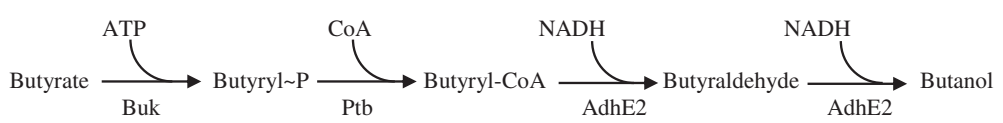

Figure 1 Metabolic pathway of Clostridium acetobutylicum engineered in E. coli. Abbreviations: Buk - butyrate kinase, Ptb - phosphotransbutyrylase, AdhE2 - aldehyde-alcohol dehydrogenase.

(A)

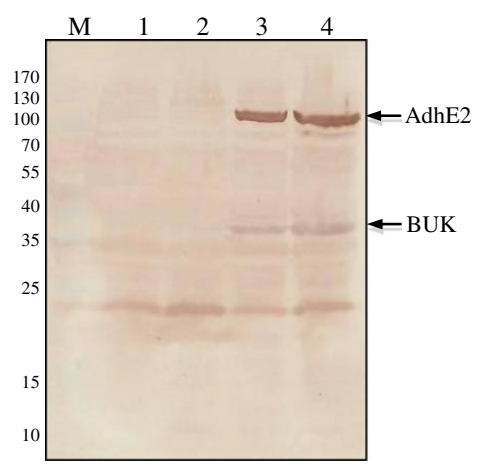

(B)

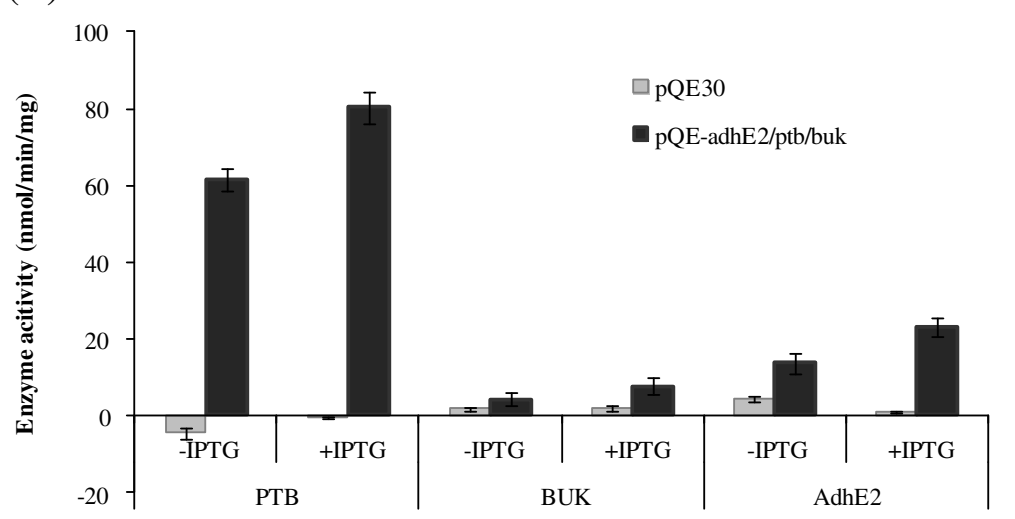

(C)

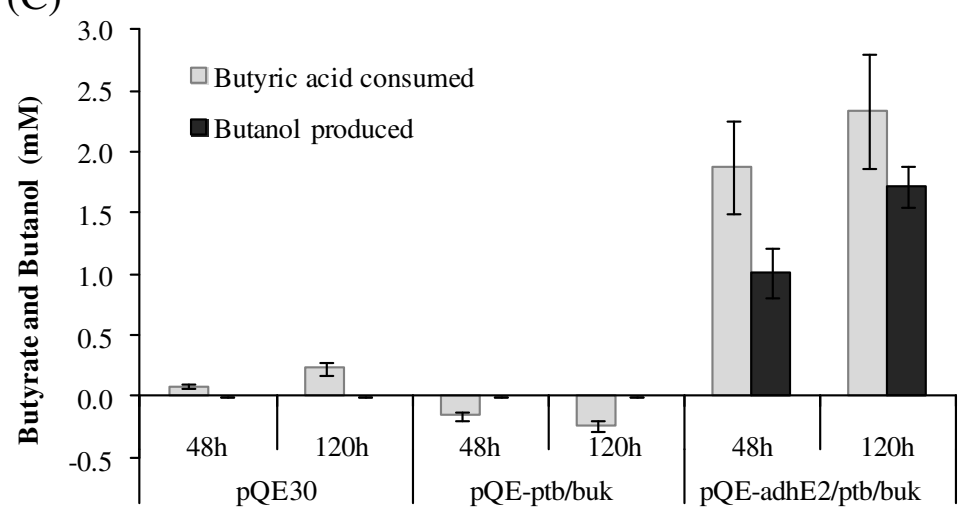

Figure 2 Expression of clostridial pathway enzymes in E. coli for conversion of butyric acid to butanol. (A) The DH5a strain containing test and control plasmids were grown in LB medium in presence or absence of IPTG and analyzed for the expression of aldehyde/alcohol dehydrogenase (AdhE2) and butyrate kinase (Buk) containing 6-histidine tag on Western blot. Lane M - Molecular weight marker; lane 1 - pQE30 - IPTG; lane 2 pQE30 + IPTG; lane 3 - pQE-adhE2/ptb/buk - IPTG; lane 4 - pQE-adhE2/ptb/buk + IPTG. (B) The grown cells in the LB medium were permeabilized with chloroform and analyzed for the activity of phosphotransbutyrylase (Ptb), Buk and AdhE2. (C) Cells containing control and test plasmids were grown in LB medium containing $10 \mathrm{mM}$ butyric acid and samples were withdrawn after $48 \mathrm{~h}$ and $120 \mathrm{~h}$ to test for butanol production. 


\section{Butyric acid tolerance and substrate preference of engineered $E$. coli}

For conversion of butyric acid to butanol, it was necessary to investigate the tolerance level of butyric acid to the $E$. coli host strain. We found that butyric acid concentration beyond $100 \mathrm{mM}$ was inhibitory to both cell growth and butanol production (Figure 3A). Four fold higher cell density at the time of induction and butyric acid addition did not improve the tolerance level beyond $100 \mathrm{mM}$ (Figure 3B), though the conversion yield was higher with butanol concentration reaching to $53 \mathrm{mM}$ as against $33 \mathrm{mM}$ for lower cell density. At every concentration of butyric acid tested, there was some butyric acid remained unutilized at the end of cultivation (Additional file 1: Table S1). This observation highlighted need for in-depth study for transport mechanism of butyric acid in E. coli.

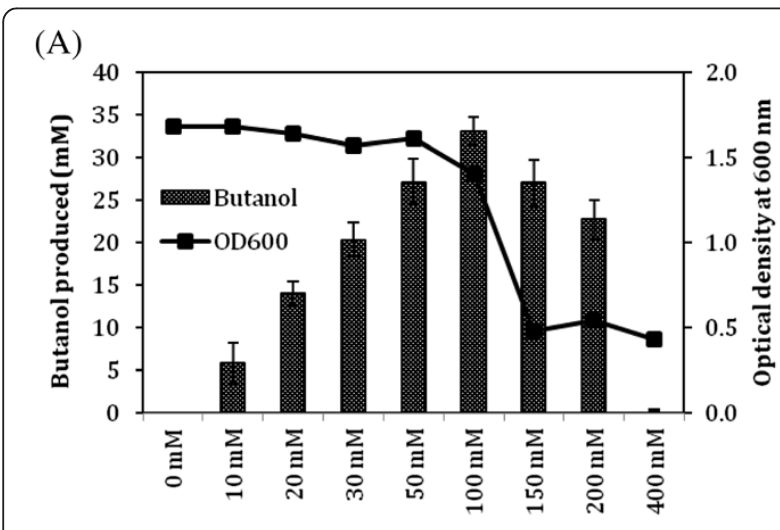

Initial butyric acid conc. in the medium

(B)

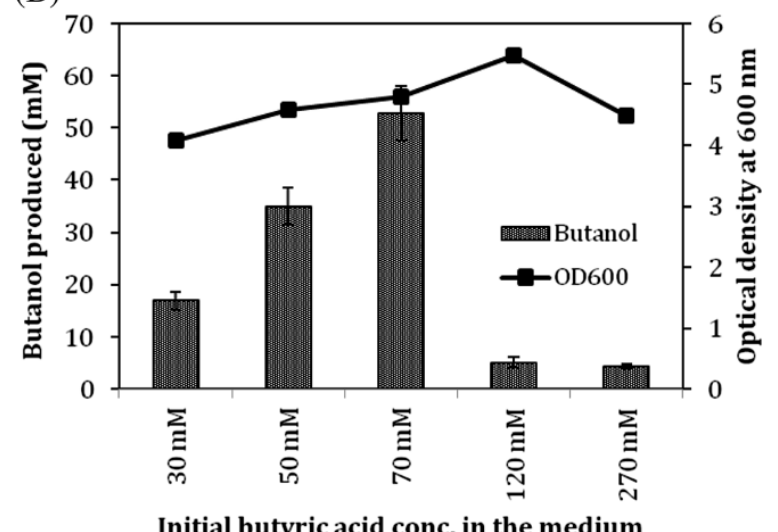

Figure 3 Butyrate tolerance level of engineered $\boldsymbol{E}$. coli. The MG1655 strain containing pQE-adhE2/ptb/buk plasmid was grown under anaerobic condition and resuspended in TB medium containing various concentration of butyric acid and $100 \mathrm{mM}$ glycerol to achieve $\mathrm{OD}_{600}$ of either 1 (A) or 5 (B). The butanol production and cell density were monitored after $120 \mathrm{~h}$ of growth in the sealed bottle under anaerobic condition.
Butanol production from butyric acid would need one ATP and two NADH (Figure 1). Therefore an optimal electron donor that could satisfy both the requirements needed to be identified. We compared glucose and glycerol as energy and electron source for butanol production. While butanol yield with respect to butyric acid was similar ( $>85 \%$ of theoretical maxima) for either of the substrate, butanol yield with respect to glycerol was approximately doubled as compared to that of glucose (Figure 4A). We further tested butyric acid uptake and butanol production kinetics with respect to various ratios of glycerol and butyric acid. Two ratios of glycerol and butyric acid, 1:1 and 1.5:1, were tested at three different concentrations (Figure 4B). Maximum butanol concentration was obtained when glycerol to butyric acid ratio was 45:30 (mM:mM).

Since glycerol to butyric acid ratio of $1.5: 1$ worked best for butanol production, we analyzed the effect of increased biocatalyst on butanol production when higher amount of substrates in the same ratio was used. The experiments were performed using biomass with optical density at $600 \mathrm{~nm}$ of 10 . With this cell density, we first tested impact of growing cells under aerobic vs anaerobic condition before resuspending the culture at $\mathrm{OD}_{600}$ of 10 and shifting to anaerobic condition for conversion of butyric acid to butanol. Aerobic cultivation will help achieving the higher cell density faster and therefore will save significant time. However, the results indicated that butanol production was three fold lower when cells were grown under aerobic condition as compared to those grown under anaerobic condition (Figure 4C). We further tested higher concentration of butyric acid, ranging from $50 \mathrm{mM}$ to $110 \mathrm{mM}$, in the culture media by growing cells under anaerobic condition. Maximum butanol concentration of $\sim 60 \mathrm{mM}$ was obtained when butyric acid concentration in the medium was $90 \mathrm{mM}$ (Figure 4C).

\section{Conversion of other short chain fatty acids to alcohols}

We tested the ability of the engineered strain for conversion of other short chain fatty acids of chain length $\mathrm{C} 2-\mathrm{C} 8$ to their corresponding alcohols. We considered acetic acid, propionic acid, butyric acid, isobutyric acid, pentanoic acid, isopentanoic acid, hexanoic acid, heptanoic acid and octanoic acid in our study. The engineered E. coli cells containing the clostridial pathway converted all the fatty acids, except octanoic acid, into their corresponding alcohols (Figure 5). The control E. coli cells with empty plasmid only converted acetic acid and to a certain extent propionic acid into their corresponding alcohols. The yield of conversion by the engineered $E$. coli varied with chain length as $\mathrm{C} 4>\mathrm{C} 3>\mathrm{C} 5>\mathrm{C} 6=\mathrm{C} 7>\mathrm{C} 8$. The conversion yield was higher with the linear chain fatty acids as compared to the branched chain fatty acids (Figure 5, Additional file 1: Table S2). 

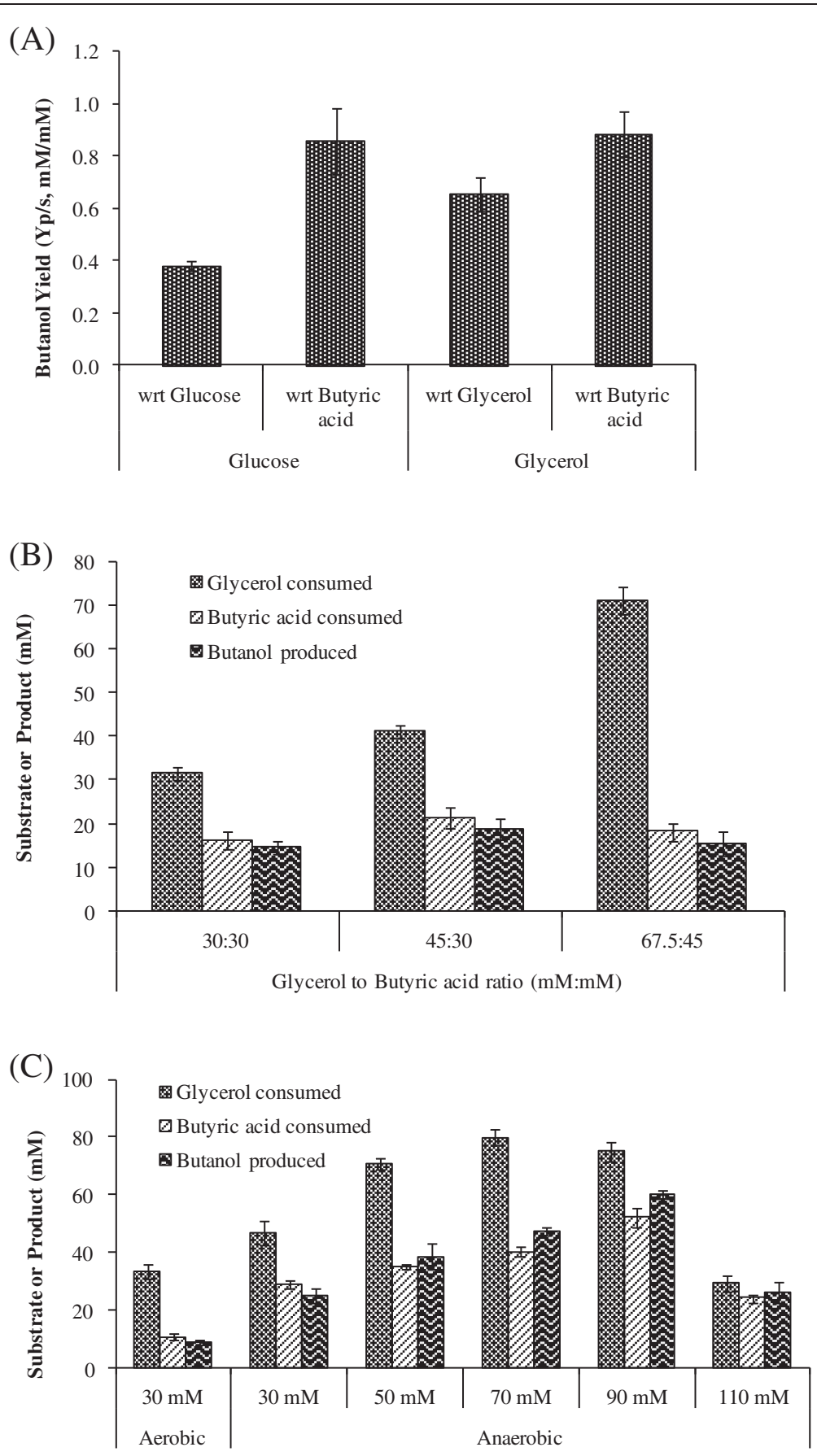

Initial Butyric acid concentration

Figure 4 Substrate specificity and substrate ratio for butanol production. (A) Impact of electron donor on butanol yield. Engineered $E$. coli MG1655 (pQE-adhE2/ptb/buk) strain was grown under anaerobic condition and resuspended in Terrific Broth with $40 \mathrm{mM}$ butyric acid and $40 \mathrm{mM}$ of either glucose or glycerol as electron donor. Various substrates consumed and butanol produced were analyzed through HPLC after $120 \mathrm{~h}$ of incubation. The butanol yield was calculated with respect to (wrt) each carbon source. (B) Different ratios of glycerol and butyric acid were tested for production of butanol using cells at the $\mathrm{OD}_{600}$ of 1.0. (C) Different butyric acid concentrations were tested for production of butanol using cells at the $\mathrm{OD}_{600}$ of 10 by keeping the glycerol to butyric acid ratio fixed at 1.5:1.

\section{Strain specificity for production of butanol}

We tested three commonly used laboratory E. coli strains, i.e., E. coli M15, E. coli MG1655 and E. coli B, for their ability to convert butyric acid into butanol when transformed with pQE-adhE2/ptb/buk plasmid. All three strains were grown under similar conditions and analyzed for butanol 


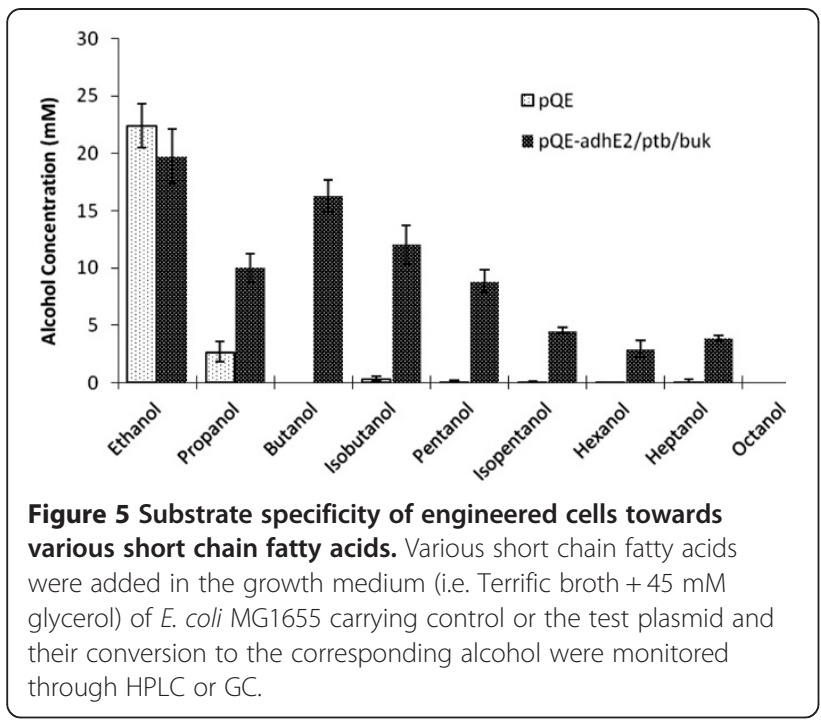

production. E. coli MG1655 was able to produce maximum amount of butanol (23 $\mathrm{mM})$ as compared to E. coli M15 $(7.8 \mathrm{mM})$ and E. coli $\mathrm{B}(0.84 \mathrm{mM})$ (Figure $6 \mathrm{~A})$, and therefore was selected for further studies. The results suggest that transport ability of different $E$. coli stains for butyric acid may vary significantly. This observation may also be applicable to other studies where E. coli was used to convert long chain fatty acids to either alcohol or alka(e)ne $[18,19]$.

E. coli MG1655 strain transformed with butyric acid to butanol pathway produced three products besides butanol, i.e., succinic acid, acetic acid and ethanol, when glycerol and butyric acid were used as substrate. Among these, succinic acid and ethanol were sink for NADH since production of each of these molecules from glycolytic intermediates would need 2 molecules of NADH (Additional file 1: Figure S1). Thus, these two molecules were the major competing products for butanol in terms of NADH requirement. We therefore tested deletion mutants for internal alcohol dehydrogenase $(a d h E)$ and fumarate reductase $(f r d A)$ in order to prevent formation of ethanol and succinate, respectively. However, these deletions did not lead to enhancement of butanol production (data not shown).

\section{Role of internal acyl-CoA synthetase in the conversion of butyric acid to butanol}

E. coli has an internal enzyme, acyl coenzyme A synthetase, encoded by $f a d D$ gene that facilitates long chain fatty acids uptake and esterification into CoA thioesters prior to its degradation via $\beta$-oxidation or incorporation into phospholipids. This enzyme converts free fatty acids into corresponding acyl-CoA with concomitant hydrolysis of ATP into AMP. We wanted to investigate whether FadD had any role to play in the uptake and conversion of butyric acid to butyryl-CoA. When E. coli MG1655 was transformed with only alcohol dehydrogenase (AdhE2) from $C$. acetobutylicum, negligible amount of butyric acid was consumed and no butanol was detected in the medium (Figure 6B), suggesting no indigenous enzyme was helping uptake of butyric acid and its assimilation into butyryl-CoA that could be further channeled through AdhE2 to butanol. Moreover, transformation of pQEadhE2/ptb/buk plasmid, which contained pathway for conversion of butyric acid to butanol from C. acetobutylicum, into $f a d D$ deleted strain resulted in similar butyric acid uptake and butanol production as that of wild type strain, indicating that FadD had no role to play in converting butyric acid to butanol.

\section{Butanol production by the engineered $E$. coli in the bioreactor}

Butanol production was analyzed under controlled bioreactor environment, which was necessary to eventually develop a scalable process. Cells were grown under anaerobic condition in the flask, harvested and resuspended in TB medium and grown further in a bioreactor in presence of butyric acid and glycerol as mentioned in the Methods section. The cells produced $25 \mathrm{mM}$ butanol from butyric acid at close to $100 \%$ conversion efficiency (Figure 7A). Enzyme kinetic studies during the cultivation indicated consistent production of the three heterologous enzymes in E. coli, i.e., Buk, Ptb and AdhE2 (Figure 7B). However, decline in Buk activity, which is the first enzyme in the butyric acid to butanol pathway, towards the end of cultivation might explain decline in flux towards butanol production. Glycerol present in the medium was used by the cells as the source of electron and ATP, which was obvious from the corresponding production of acetate (Figure 7A). To improve the titer and productivity of butanol, we carried out cultivation study in the bioreactor with the starting cell density of $\mathrm{OD}_{600} \sim 10$. The butanol titer reached to $60 \mathrm{mM}$ within $24 \mathrm{hr}$ of fermentation (Figure 7C), as against $25 \mathrm{mM}$ butanol in $100 \mathrm{hr}$ when low cell density was used (Figure 7A).

We further tested continuous production of butanol by cell recycling through hollow-fiber cassette. The feed containing butyric acid and glycerol was started continuously at the rate of $15 \mathrm{mmol} / \mathrm{l} / \mathrm{h}$ and $22.5 \mathrm{mmol} / \mathrm{l} / \mathrm{h}$, respectively, with the dilution rate of $0.2 \mathrm{~h}^{-1}$ after $24 \mathrm{hr}$ of fermentation with $\mathrm{OD}_{600}$ of 10 . The butanol concentration was observed in the permeate intermittently until $240 \mathrm{hrs}$. An average butanol titer of $37 \mathrm{mM}$ and productivity of $7.6 \mathrm{mmol} / \mathrm{l} / \mathrm{h}$ was observed in the permeate during the continuous cultivation (Figure $7 \mathrm{C}$ ). There was a corresponding consumption of butyric acid at the similar rate. Though the butanol production rate was considerably lower than what is expected at the commercial scale, 


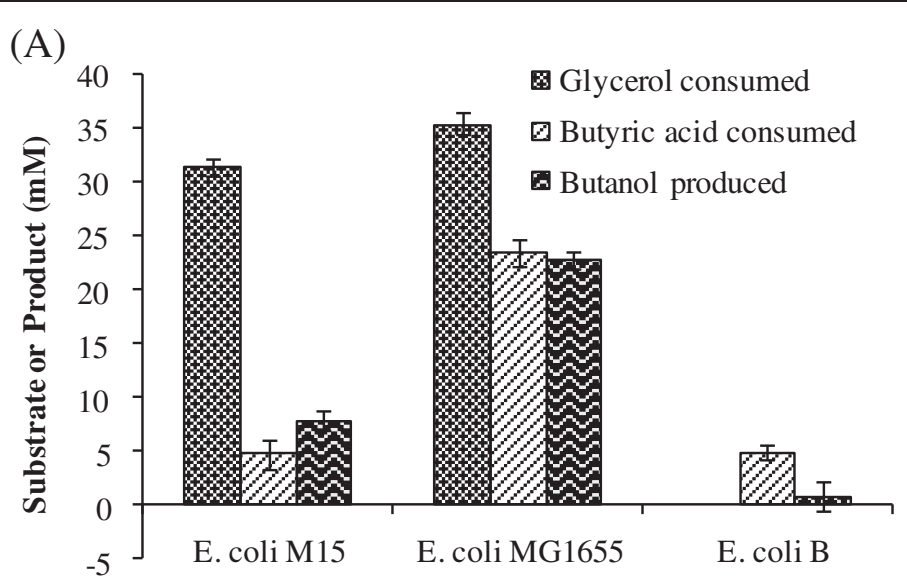

(B)

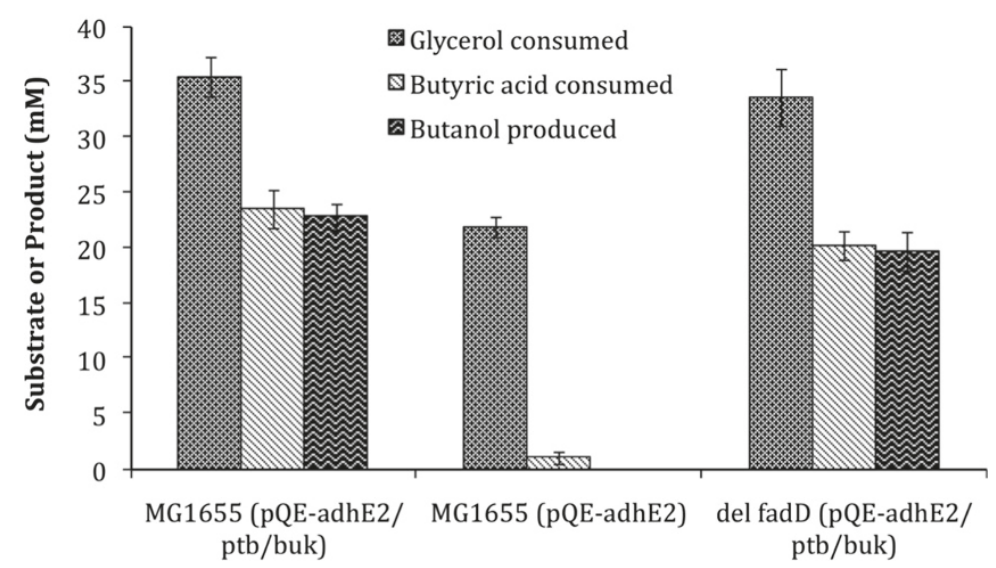

Figure 6 Strain specificity of engineered cells on the uptake of butyric acid and production of butanol. Effect of strain type (A) and fadD gene deletion (B) on butyric acid uptake and butanol production was monitored by growing the strains anaerobically in Terrific broth medium containing $45 \mathrm{mM}$ glycerol and $30 \mathrm{mM}$ butyric acid and determining the metabolites through HPLC or GC.

further process development is likely to help in improving the production rate.

\section{Conclusions}

We have shown the efficiency of clostridial pathway in E. coli for conversion of short chain fatty acids of chain length C3 - C7 to their corresponding alcohols. We also demonstrated that indigenous enzymes of $E$. coli did not play any significant role in this process. The observation that the conversion could be done in continuous mode using engineered cells as the biocatalysts justifies this process to be further optimized and assessed for commercial application.

\section{Methods}

\section{Bacterial strains, plasmids and culture conditions}

E. coli and C. acetobutylicum strains used in this study are listed in Table 1 . E. coli strains were grown at $37^{\circ} \mathrm{C}$ in
Luria-Bertani (LB) medium or Terrific Broth (TB) medium along with $100 \mu \mathrm{g} / \mathrm{ml}$ ampicillin, $30 \mu \mathrm{g} / \mathrm{ml}$ kanamycin and $0.1 \mathrm{mM}$ IPTG as per requirement. All deletion mutant E. coli strains used in this study were procured from CGSC (Coli Genetic Stock Centre, Yale University, USA). E. coli strains DH5a and M15 were obtained from Invitrogen and Qiagen, respectively. C. acetobutylicum ATCC 824 was procured from American Type Culture Collection (ATCC), USA. C. acetobutylicum was grown in Reinforced Clostridial Medium (RCM, Himedia Laboratories) in an anaerobic chamber maintained at $37^{\circ} \mathrm{C}$. E. coli DH5a strain was used for making all the plasmid constructs and pQE30 (Qiagen) was used as expression vector for all the genes. Recombinant DNA techniques were done as per standard procedures [30]. Restriction enzymes and T4 DNA ligase were procured from New England Biolabs (NEB). Plasmid isolation was performed using the kit from Himedia and DNA purification was done using 


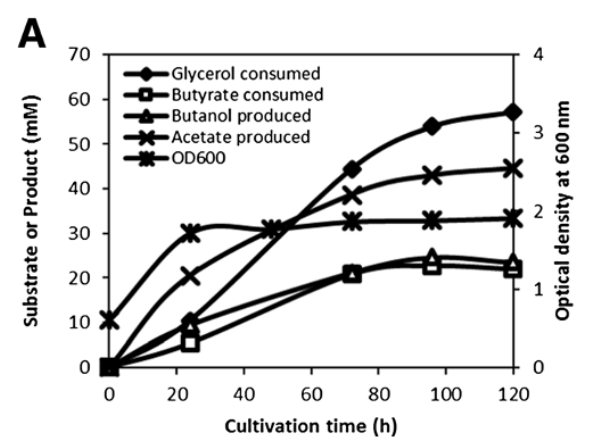

C

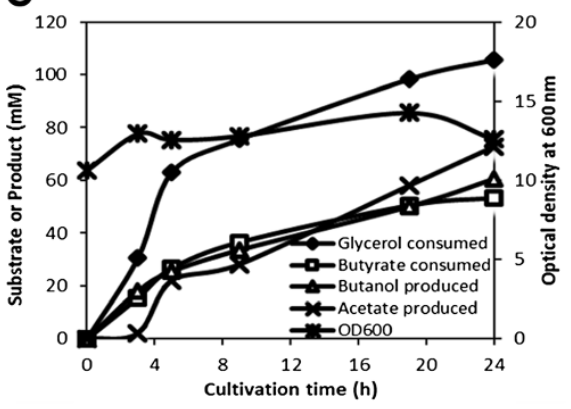

B

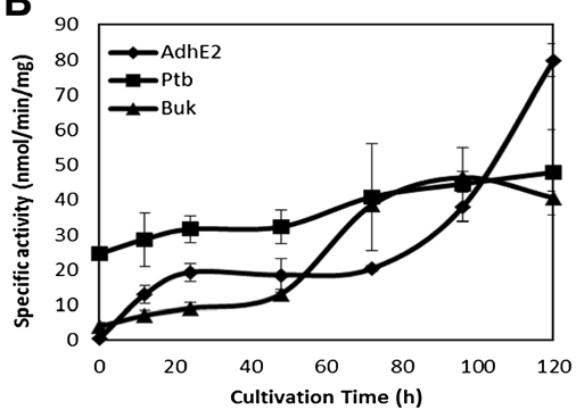

D

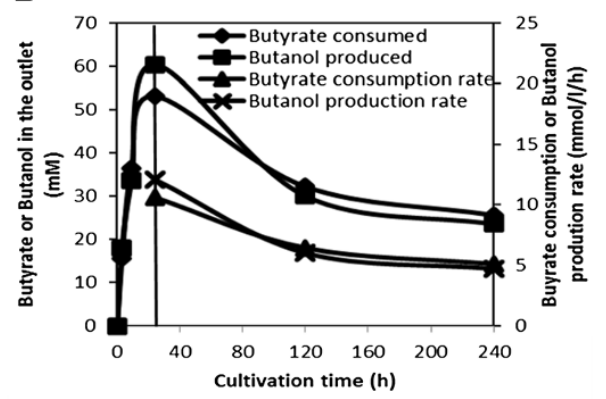

Figure 7 Production of butanol in the bioreactor in batch and continuous mode. (A) Fermentation profile and (B) enzyme kinetics of the E. coli MG1655 (pQE-adhE2/ptb/buk) strain in a bioreactor cultivated in the batch mode with an initial $\mathrm{OD}_{600}$ of 1.0. (C) Fermentation profile of the engineered strain with an initial $\mathrm{OD}_{600}$ of 10. (D) Butyric acid consumption and butanol production kinetics in the bioreactor operated under continuous mode with cell recycling using hollow fiber module. Vertical bar at $24 \mathrm{hr}$ indicates the position where fermentation was shifted from batch mode to continuous mode at the dilution rate of $0.2 \mathrm{~h}^{-1}$.

the Sure-Extract PCR Cleanup and Gel Extraction Kit from Genetix. Oligonucleotides to be used as primers were custom synthesized from Sigma-Aldrich. PCR amplification was done using Phusion High Fidelity DNA Polymerase (Finnzymes) and Taq Polymerase (Bangalore Genei). All chemicals used in this study were procured from Sigma-Aldrich.

Transformed E. coli strains were streaked on LB agar plates containing $100 \mu \mathrm{g} / \mathrm{ml}$ ampicillin and/or $30 \mu \mathrm{g} / \mathrm{ml}$ kanamycin and grown overnight at $37^{\circ} \mathrm{C}$. Isolated colonies were used to prepare primary inoculum by inoculating in $5 \mathrm{ml} \mathrm{LB}$ medium containing antibiotics and growing overnight aerobically. The overnight culture was used to prepare secondary inoculum by inoculating in $20 \mathrm{ml} \mathrm{TB}$ medium containing $50 \mathrm{mM}$ glucose or glycerol and incubating overnight at $37^{\circ} \mathrm{C}$ under anaerobic conditions. The grown secondary inoculum was harvested, resuspended in $20 \mathrm{ml}$ of $\mathrm{TB}$ medium to achieve an $\mathrm{OD}_{600}$ of 1.0 and transferred in a $100 \mathrm{ml}$ rubber stoppered anaerobic bottle purged with argon gas. The TB medium also contained butyric acid and $0.1 \mathrm{mM}$ IPTG in addition to the appropriate carbon source. The bottle was purged with argon and the culture was grown at $37^{\circ} \mathrm{C}$ in an orbital shaker. Samples were withdrawn from the bottles at appropriate time points for cell density and metabolite analysis.
The strains were also grown under controlled conditions in a bioreactor. A primary culture was prepared by inoculating an isolated colony in LB and growing the cells overnight at $37^{\circ} \mathrm{C}$. The grown culture was used to inoculate $350 \mathrm{ml}$ TB medium in $1 \mathrm{~L}$ conical flask containing either glucose or glycerol and incubated for 24 hours in an anaerobic chamber maintained at $37^{\circ} \mathrm{C}$. An appropriate volume of this culture was harvested and inoculated in the bioreactor vessel (Multi-vessel BioStat Q Plus fermentor, Sartorius) containing $350 \mathrm{ml}$ of TB medium along with glycerol and butyric acid so as to achieve an initial $\mathrm{OD}_{600}$ of 1 or 10. IPTG was not added in the bioreactor as it was shown at the small scale that addition of IPTG had no impact on conversion of butyric acid into butanol (data not shown), perhaps due to sufficient basal level expression of the pathway enzymes. The bioreactor was maintained at $37^{\circ} \mathrm{C}$ with a stirrer speed of $300 \mathrm{rpm}, \mathrm{pH}$ of 7 and purging of highly pure grade argon at a rate of $0.01 \mathrm{~L} / \mathrm{min}$ to maintain the anaerobic environment.

Continuous production of butanol was achieved by cell recycling using a Hollow Fiber Cartridge (surface area $420 \mathrm{~cm}^{2}, 500,000$ NMWC) from GE Healthcare. The cultivation was carried out in a bioreactor with $350 \mathrm{ml}$ working volume under the operating conditions mentioned above with an initial cell density at $\mathrm{OD}_{600}$ of 10 . Solution 
Table 1 Strains, plasmids and primers used in this study

\begin{tabular}{|c|c|c|}
\hline Name & Description & Reference or source \\
\hline \multicolumn{3}{|l|}{ Strains } \\
\hline Clostridium acetobutylicum & & ATCC \#824 \\
\hline E. coli MG1655 & F- LAM- rph-1 & CGSC \#6300 \\
\hline E. coli $B$ & F- & CGSC \#5713 \\
\hline E. coli DH5a & $\begin{array}{l}\text { F- Ф80lacZAM15 } \Delta(\text { lacZYA-argF) U169 recA1 endA1 hsdR17 (rK-, mK+) } \\
\text { phoA supE44 } \lambda-\text { thi }^{-1} \text { gyrA96 relA1 }\end{array}$ & Invitrogen \\
\hline E. coli M15 & F- thi lac mtl, pREP4 plasmid & Qiagen \\
\hline E. coli BW25113 & rrnB DElacZ4787 HsdR514 DE(araBAD)567 DE(rhaBAD)568 rph-1 & CGSC \#7636 \\
\hline E. coli $\Delta \mathrm{fadD}$ & BW25113, $\Delta$ fadD :: FRT-kan-FRT & CGSC \#9503 \\
\hline E. coli $\Delta$ adhE & BW25113, $\Delta$ adhe ::FRT-kan-FRT & CGSC \#9113 \\
\hline E. coli $\Delta$ frdA & BW25113, $\Delta$ frdA $::$ FRT-kan-FRT & CGSC \#10964 \\
\hline \multicolumn{3}{|l|}{ Plasmids } \\
\hline pQE30 & bla, cloning vector & Qiagen \\
\hline pQE-adhE2 & $\begin{array}{l}\text { pQE30 with adhe2 gene from C. acetobutylicum cloned between BamHI } \\
\text { and Sall sites }\end{array}$ & This study \\
\hline pQE-ptb/buk & $\begin{array}{l}\text { pQE30 with ptb-buk operon from C. acetobutylicum cloned between } \\
\text { Sall and Pstl sites }\end{array}$ & This study \\
\hline pQE-adhE2/ptb/buk & $\begin{array}{l}\text { pQE-adhE2 with ptb-buk operon from C. acetobutylicum cloned between } \\
\text { Sall and Pstl sites }\end{array}$ & This study \\
\hline \multicolumn{3}{|l|}{ Primers* } \\
\hline P1 & ATCGGATCCATGAAAGTTACAAATCAAAAA & This study \\
\hline P2 & ACTGGTCGACTTAGTGGTGGTGGTGGTGGTGAAATGATITATATAGATATC & This study \\
\hline P3 & ACTGGTCGACGAAGGAGATATACCATGATTAAGAGTITAATGAAAT & This study \\
\hline P4 & GTCTGCAGTIAGTGGTGGTGGTGGTGGTGTTTGTATTCCTTAGCTITTC & This study \\
\hline
\end{tabular}

*Italicized nucleotides in the primers denote restriction enzyme sites.

containing $50 \mathrm{mM}$ butyric acid, $75 \mathrm{mM}$ glycerol, $72 \mathrm{mM}$ $\mathrm{K}_{2} \mathrm{HPO}_{4}$ and $17 \mathrm{mM} \mathrm{KH} \mathrm{HO}_{4}$ were added to the fermentor vessel through the peristaltic pump at the dilution rate of $0.2 \mathrm{~h}^{-1}$ to achieve feeding of $15 \mathrm{mmol} / \mathrm{l} / \mathrm{h}$ of butyric acid and $22.5 \mathrm{mmol} / \mathrm{l} / \mathrm{h}$ of glycerol. Medium along with cells was pumped through the hollow fiber cassette. The cells were recycled back to the bioreactor while permeate from hollow fiber cassette containing butanol was recovered and used for analysis of butanol formation.

\section{Cloning of C. acetobutylicum genes in E. coli}

Total genomic DNA was isolated from $C$. acetobutylicum ATCC 824 as per standard procedure [30]. The adhE2 gene of $C$. acetobutylicum was PCR amplified using P1 and P2 primers, digested with BamHI and SalI restriction enzymes and ligated to the corresponding restriction sites of $\mathrm{pQE} 30$ plasmid to obtain $\mathrm{pQE}$-adhE2. The P2 primer also contained codons for 6-histidine tag to monitor the expression at the protein level. The $p t b-$ buk operon of C. acetobutylicum ATCC 824 encoding phosphotransbutyrylase and butyric acid kinase genes was amplified from the genomic DNA using the P3 and $\mathrm{P} 4$ primers. The PCR product was digested with
SalI and PstI restriction enzymes and ligated to the corresponding restriction sites of $\mathrm{pQE} 30$ plasmid to obtain $\mathrm{pQE}-\mathrm{ptb} / \mathrm{buk}$. P3 primer contained ribosomal biding site for translation initiation and $\mathrm{P} 4$ primer contained codons for 6-histidine tag to monitor the expression of operon at the protein level. The adhE2 gene was further cloned at the BamHI and SalI restriction sites of $\mathrm{pQE}-\mathrm{ptb} / \mathrm{buk}$ plasmid to obtain the final construct pQE-adhE2/ptb/buk.

The expression of the cloned genes was confirmed by SDS - PAGE and Western Blotting. Briefly, the cultures were induced and the crude cell lysates obtained were separated on a $12 \%$ polyacrylamide gel. The proteins were transferred to a nitrocellulose membrane $(0.2 \mathrm{um}$, BioTraceNT, Pall Corporation), probed with anti penta-his antibody (H1029, Sigma) followed by HRPconjugated anti-mouse IgG antibody (A4416, Sigma). Color development of the blot was performed using DAB (diaminobenzidine) and hydrogen peroxide.

\section{Analytical methods}

For extracellular metabolite analysis, cells were centrifuged at $13000 \mathrm{rpm}$ for $10 \mathrm{~min}$ and the supernatant was filtered 
through $0.22 \mu \mathrm{m}$ membrane. The extracellular metabolites were analyzed on a 1260 Infinity Series HPLC system (Agilent) equipped with an Aminex HPX-87H anion exchange column (Bio-Rad). Filtered and degassed $4 \mathrm{mM} \mathrm{H}_{2} \mathrm{SO}_{4}$ was used as the mobile phase at a flow rate $0.3 \mathrm{ml} / \mathrm{min}$. The column was maintained at a temperature of $40^{\circ} \mathrm{C}$ in a thermostat chamber. Butanol was analyzed on a $7890 \mathrm{~A}$ gas chromatography system (Agilent) with a flame ionization detector equipped with a 7694E headspace analyzer using a HP- 5 column (30 m length, $0.32 \mathrm{~mm}$ id, 0.25 um film thickness). The oven program was set as follows $\left(40^{\circ} \mathrm{C}\right.$ for 4 minutes, $80^{\circ} \mathrm{C}$ for 4 minutes at $10^{\circ} \mathrm{C} / \mathrm{min}, 120^{\circ} \mathrm{C}$ for $2 \mathrm{~min}$ at $20^{\circ} \mathrm{C} / \mathrm{min}, 200^{\circ} \mathrm{C}$ for $2 \mathrm{~min}$ at $20^{\circ} \mathrm{C} / \mathrm{min}$ ). The inlet and detector were maintained at $150^{\circ} \mathrm{C}$ and $280^{\circ} \mathrm{C}$, respectively. Metabolite concentrations were calculated from the area of the curve obtained for $1 \mathrm{~g} / \mathrm{l}$ of the standards (Absolute Standard). All results were presented as average and standard deviation of the data from two independent experiments.

\section{Enzyme assays}

Phosphotransbutyrylase (Ptb) activity was measured by estimating the liberation of coenzyme $\mathrm{A}$ on the addition of butyryl CoA to the reaction mixture. The free coenzyme A formed was then allowed to form a coloured complex with $5,5^{\prime}$ - dithio-(2-nitrobenzoic acid) (DTNB) which could then be estimated by measuring the absorbance at $412 \mathrm{~nm}$ [31]. The reaction mixture contained $100 \mathrm{mM}$ potassium phosphate buffer (pH 7.4), $0.02 \mathrm{mM}$ butyryl CoA, $0.08 \mathrm{mM}$ DTNB and crude cell extract. The extinction coefficient of the DTNB - CoA - SH complex was taken as $13.6 \mathrm{mM}^{-1} \mathrm{~cm}^{-1}$. Aldehyde/alcohol dehydrogenase (AdhE2) activity was measured in the reverse direction by estimating the amount of free NADH liberated during the reaction [32]. Briefly the reaction mixture contained $19 \mathrm{mM}$ sodium pyrophosphate buffer ( $\mathrm{pH} 8.8$ ), $2.37 \% \mathrm{v} / \mathrm{v}$ ethanol or butanol, $5 \mathrm{mM} \beta$ - NAD and crude cell extract in a total volume of $2 \mathrm{ml}$. The absorbance at $340 \mathrm{~nm}$ was monitored to estimate the amount of free NADH produced. The extinction coefficient of NADH at $340 \mathrm{~nm}$ was taken as $6.22 \mathrm{mM}^{-1} \mathrm{~cm}^{-1}$. The activity of butyrate kinase (Buk) was estimated by monitoring the formation of the coloured ferric hydroxamate complex with butyryl phosphate in the presence of excess of hydroxylamine [33]. The reaction mixture contained $770 \mathrm{mM}$ potassium butyrate (pH 7.5), $48 \mathrm{mM}$ Tris - Cl, $10 \mathrm{mM} \mathrm{MgSO} 4,700 \mathrm{mM} \mathrm{KOH,}$ $10 \mathrm{mM}$ ATP and crude cell extract. The reaction was initiated by the addition of ATP and the mixture was incubated at $37^{\circ} \mathrm{C}$ for 5 minutes. $1 \mathrm{ml}$ of $10 \%$ trichloroacetic acid was used to stop the reaction and the end product was estimated by the addition of $4 \mathrm{ml}$ of $\mathrm{FeCl}_{3}(1.25 \%$ in $1 \mathrm{~N} \mathrm{HCl})$. The extinction coefficient of the hydroxamate complex at $540 \mathrm{~nm}$ was taken as $0.691 \mathrm{mM}^{-1} \mathrm{~cm}^{-1}$. The enzyme units were represented as $\mathrm{nmol} / \mathrm{min} / \mathrm{mg}$.

\section{Additional file}

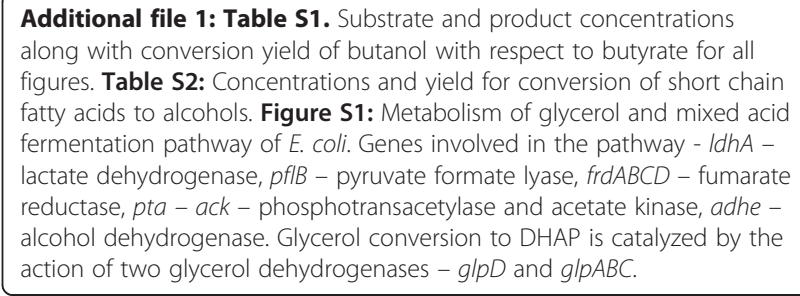

Competing interests

The authors declare that they have no competing interests.

\section{Authors' contributions}

AJM and SSY conceived the study, AJM carried-out all the experiments, AJM and SSY analyzed all the data, SSY drafted the manuscript. All authors read and approved the final manuscript.

\section{Acknowledgements}

We thank Dr Alok Kumar Malaviya for the help in setting-up the hollow fiber based cell recycling system. We acknowledge financial support from Department of Biotechnology (DBT), Govt of India. AJM was supported by a fellowship from Council of Scientific and Industrial Research.

Received: 21 May 2013 Accepted: 4 September 2013

Published: 10 September 2013

\section{References}

1. Bhattarai K, Stalick WM, McKay S, Geme G, Bhattarai N: Biofuel: an alternative to fossil fuel for alleviating world energy and economic crises. J Environ Sci Health A Tox Hazard Subst Environ Eng 2011, 46:1424-1442.

2. Mussatto SI, Dragone G, Guimarães PM, Silva JP, Carneiro LM, Roberto IC, Vicente A, Domingues L, Teixeira JA: Technological trends, global market, and challenges of bio-ethanol production. Biotechnol Adv 2010, 28:817-830.

3. Jin C, Yao M, Liu H, Leed CF, Ji J: Progress in the production and application of n-butanol as a biofuel. Renew Sustain Energy Rev 2011, 15:4080-4106.

4. Green EM: Fermentative production of butanol-the industrial perspective. Curr Opin Biotechnol 2011, 22:337-343.

5. Dürre P: Biobutanol: an attractive biofuel. Biotechnol J 2007, 2:1525-1534.

6. Gheshlaghi R, Scharer JM, Moo-Young M, Chou CP: Metabolic pathways of clostridia for producing butanol. Biotechnol Adv 2009, 27:764-781.

7. Zheng YN, Li LZ, Xian M, Ma YJ, Yang JM, Xu X, He DZ: Problems with the microbial production of butanol. J Ind Microbiol Biotechnol 2009, 36:1127-1138.

8. Atsumi S, Cann AF, Connor MR, Shen CR, Smith KM, Brynildsen MP, Chou KJ, Hanai T, Liao JC: Metabolic engineering of Escherichia coli for 1-butanol production. Metab Eng 2008, 10:305-311.

9. Inui M, Suda M, Kimura S, Yasuda K, Suzuki H, Toda H, Yamamoto S, Okino $\mathrm{S}$, Suzuki N, Yukawa H: Expression of Clostridium acetobutylicum butanol synthetic genes in Escherichia coli. Appl Microbiol Biotechnol 2008, 77:1305-1316.

10. Chen SK, Chin WC, Tsuge K, Huang CC, Li SY: Fermentation approach for enhancing 1-butanol production using engineered butanologenic Escherichia coli. Bioresour Technol 2013, 145:204-209.

11. Steen EJ, Chan R, Prasad N, Myers S, Petzold CJ, Redding A, Ouellet M, Keasling JD: Metabolic engineering of Saccharomyces cerevisiae for the production of n-butanol. Microb Cell Fact 2008, 7:36.

12. Shen CR, Lan El, Dekishima Y, Baez A, Cho KM, Liao JC: Driving forces enable high-titer anaerobic 1-butanol synthesis in Escherichia coli. Appl Environ Microbiol 2011, 77:2905-2915.

13. Lennen RM, Pfleger BF: Engineering Escherichia coli to synthesize free fatty acids. Trends Biotechnol 2012, 30:659-667.

14. Steen EJ, Kang Y, Bokinsky G, Hu Z, Schirmer A, McClure A, Del Cardayre SB, Keasling JD: Microbial production of fatty-acid-derived fuels and chemicals from plant biomass. Nature 2010, 463:559-562.

15. Zhang F, Ouellet M, Batth TS, Adams PD, Petzold CJ, Mukhopadhyay A, Keasling JD: Enhancing fatty acid production by the expression of the regulatory transcription factor FadR. Metab Eng 2012, 14:653-660. 
16. Zhang C, Yang H, Yang F, Ma Y: Current progress on butyric acid production by fermentation. Curr Microbiol 2009, 59:656-663.

17. Wei D, Liu X, Yang ST: Butyric acid production from sugarcane bagasse hydrolysate by Clostridium tyrobutyricum immobilized in a fibrous-bed bioreactor. Bioresour Technol 2013, 129:553-560.

18. Howard TP, Middelhaufe S, Moore K, Edner C, Kolak DM, Taylor GN, Parker DA, Lee R, Smirnoff N, Aves SJ, Love J: Synthesis of customized petroleumreplica fuel molecules by targeted modification of free fatty acid pools in Escherichia coli. Proc Natl Acad Sci U S A 2013, 110:7636-7641.

19. Akhtar MK, Turner NJ, Jones PR: Carboxylic acid reductase is a versatile enzyme for the conversion of fatty acids into fuels and chemical commodities. Proc Natl Acad Sci U S A 2013, 110:87-92.

20. Richter H, Qureshi N, Heger S, Dien B, Cotta MA, Angenent LT: Prolonged conversion of $n$-butyrate to $n$-butanol with Clostridium saccharoperbutylacetonicum in a two-stage continuous culture with in-situ product removal. Biotechnol Bioeng 2012, 109:913-921.

21. Baba S, Tashiro Y, Shinto H, Sonomoto K: Development of high-speed and highly efficient butanol production systems from butyric acid with high density of living cells of Clostridium saccharoperbutylacetonicum. J Biotechnol 2012, 157:605-612.

22. Tashiro Y, Shinto H, Hayashi M, Baba S, Kobayashi G, Sonomoto K: Novel high-efficient butanol production from butyrate by non-growing Clostridium saccharoperbutylacetonicum N1-4 (ATCC 13564) with methyl viologen. J Biosci Bioeng 2007, 104:238-240.

23. Jurgens $G$, Survase $S$, Berezina O, Sklavounos E, Linnekoski J, Kurkijärvi A, Väkevä $M$, van Heiningen A, Granström T: Butanol production from lignocellulosics. Biotechnol Lett 2012, 34:1415-1434.

24. Cary JW, Petersen DJ, Papoutsakis ET, Bennett GN: Cloning and expression of Clostridium acetobutylicum phosphotransbutyrylase and butyrate kinase genes in Escherichia coli. J Bacteriol 1988, 170:4613-4618.

25. Clark SW, Bennett GN, Rudolph FB: Isolation and characterization of mutants of Clostridium acetobutylicum ATCC 824 deficient in acetoacetyl-Coenzyme A:Acetate/Butyrate:Coenzyme A-Transferase (EC 2.8.3.9) and in Other Solvent Pathway Enzymes. Appl Environ Microbiol 1989, 55:970-976.

26. Black PN, DiRusso CC, Metzger AK, Heimert TL: Cloning, sequencing, and expression of the fadD gene of Escherichia coli encoding acyl coenzyme a synthetase. J Biol Chem 1992, 267:25513-25520.

27. Fontaine L, Meynial- Salles I, Girbai L, Yang X, Croux C, Soucaille P: Molecular characterization and transcriptional analysis of adhE2, the gene encoding the NADH - dependent aldehyde/alcohol dehydrogenase responsible for butanol production in alcohologenic cultures of Clostridium acetobutylicum ATCC 824. J Bacteriol 2002, 184:821-830.

28. Hartmanis MG: Butyrate kinase from Clostridium acetobutylicum. J Biol Chem 1987, 262:617-621

29. Berezina OV, Zakharova NV, Brandt A, Yarotsky SV, Schwarz WH, Zverlov W: Reconstructing the clostridial $n$-butanol metabolic pathway in Lactobacillus brevis. Appl Microbiol Biotechnol 2010, 87:635-646.

30. Sambrook J, Fritsch EF, Maniatis T: Molecular cloning, a laboratory manual. 2nd edition. Cold Spring Harbour, NY: Cold Spring Harbor Laboratory Press; 1989.

31. Andersch W, Bahl H, Gottschalk G: Level of enzymes involved in acetate, butyrate, acetone and butanol formation by Clostridium acetobutylicum. Eur J Appl Microbiol Biotechnol 1983, 18:327-333.

32. Kagi J, Vallee B: The role of zinc in alcohol dehydrogenase: the effect of metal binding agents on the structure of the yeast alcohol dehydrogenase molecule. J Biol Chem 1960, 235:3188-3192.

33. Rose IA: Acetate kinase of bacteria (acetokinase). Methods Enzymol 1955, 1:591-593.

doi:10.1186/1754-6834-6-128

Cite this article as: Mattam and Yazdani: Engineering E. coli strain for conversion of short chain fatty acids to bioalcohols. Biotechnology for Biofuels 2013 6:128.

\section{Submit your next manuscript to BioMed Central and take full advantage of:}

- Convenient online submission

- Thorough peer review

- No space constraints or color figure charges

- Immediate publication on acceptance

- Inclusion in PubMed, CAS, Scopus and Google Scholar

- Research which is freely available for redistribution

Submit your manuscript at www.biomedcentral.com/submit 